\title{
Vaccine Potency
}

National Cancer Institute

\section{Source}

National Cancer Institute. Vaccine Potency. NCI Thesaurus. Code C69183.

A quantitative measure of the specific ability of the vaccine product to achieve an intended biological effect defined in a suitable biological assay based on the attribute of the product that is linked to the relevant biological properties. 